\title{
Impact of Wheat (Triticum aestivum L.) Germination Process on Starch Properties for Application in Films
}

\author{
Julia Baranzelli, Dianini H. Kringel, Joao F. Mallmann, Emílio Bock, \\ Shanise L. Mello El Halal,* Luciana Prietto, Elessandra da Rosa Zavareze, \\ Martha Zavariz de Miranda, and Alvaro Renato Guerra Dias
}

Germination causes several changes in wheat grains that are necessary for growth, one of which is starch characteristics. The objective of this study is to evaluate the effects of laboratory-induced wheat germination and preharvest sprouting on starch properties, as well as to examine the application of extracted starch in films. Starch is extracted from non-germinated wheat samples; pre-harvest sprouting and germination are induced for 24,48 , and $72 \mathrm{~h}$. Starch is characterized for chemical composition, flour yield, enzymatic activity, morphology, solubility, swelling power, pasting properties, and relative crystallinity. Subsequently, films of germinated and non-germinated wheat starch are characterized by mechanical properties, thickness, opacity, water solubility, and water vapor permeability. Wheat germination is found to increase enzymatic activity, swelling power, solubility, and relative crystallinity of starch. A significant increase in film elongation is correlated with increased wheat germination time. These results indicate that germination of wheat alters starch properties and promotes production of films with attractive characteristics for future applications.

\section{Introduction}

Wheat (Triticum aestivum L.) is a widely cultivated cereal in the world and ranks third in global production after maize and rice. ${ }^{[1]}$ Starch is the main component of wheat and accounts for $65-75 \%$ of the final dry weight of grains. ${ }^{[2]}$ According to Ubeyitogullari and Ciftci, ${ }^{[3]}$ among all sources of starch, wheat starch is the third most produced type of starch in the world and plays an important role in many foods.

J. Baranzelli, Dr. D. H. Kringel, J. F. Mallmann, E. Bock,

Dr. S. L. Mello El Halal, Dr. L. Prietto, Prof. E. da Rosa Zavareze,

Prof. A. Renato Guerra Dias

Laboratory of Post-Harvest, Quality and Industrialization of Grains

Department of Food Science and Technology

Faculty of Agronomy "Eliseu Maciel"

Federal University of Pelotas

Eliseu Maciel Ave, Capão do Leão 96050-500, Brazil

E-mail: shanisemell@hotmail.com

M. Zavariz de Miranda

Grain Quality Laboratory

Brazilian Agricultural Research Corporation - Embrapa Trigo

Highway BR 285, km 294, P. O. Box 3081

99050-970 Passo Fundo, RS, Brazil

DOI: 10.1002/star.201800262
Starch has attracted considerable attention in film development as it is a biodegradable thermoplastic polymer and allows for manufacture of low-cost, flexible, and transparent films. However, films developed using natural starch present some drawbacks, including poor mechanical properties. ${ }^{[4]}$ Certain strategies have been developed to improve this aspect, such as starch modification or mixture of starch with other compounds. ${ }^{[5-6]}$ However, starch modification requires several procedures subsequent to the extraction process; this method makes film production more time-consuming and expensive when compared to the use of natural starch. In addition, coupling of starch to other polymers requires additional steps during sample preparation. In view of this, it is beneficial to find an alternative source of starch that would allow for formation of films with better technological properties when compared with those of natural starch.

Recently, studies have shown that several changes occur in germinated wheat grains, including starch. ${ }^{[7,10]}$ Currently, no studies have examined the usage of starch obtained from germinated wheat grains on film production.

Germinated wheat has traditionally been viewed as nonbeneficial since it affects the yield and quality of wheat grains and compromises the quality of the products formed; it has been regarded as unacceptable to producers and consumers. Germinated wheat grains are generally used for animal feed production, resulting in considerable economic losses. ${ }^{[11]}$ Therefore, the use of germinated grains for film production is a very attractive proposal; it provides an alternative use for these grains, as changes in starch properties can positively affect film properties.

Germination is a process that can occur naturally in the field before wheat harvest or under controlled conditions in the laboratory. Parameters such as humidity, time, and temperature can be controlled during this process; thus, the effects of degree of germination on film properties can be evaluated. ${ }^{\text {[7] }}$

Some studies showed that during wheat germination, starch is degraded by the combined actions of various hydrolytic enzymes and is transported to the embryo to meet the needs of the growing plant. ${ }^{[9]}$ Amylases produced during germination break glycosidic linkages of starch to produce single sugars (maltose, glucose, and dextrin). ${ }^{[12]}$ Moreover, according to 
Olaerts et al., ${ }^{[13]}$ wheat germination affects starch pasting properties; it reduces the binding capacity and swelling power of starch in water. Simsek et al. ${ }^{[12]}$ also reported that wheat germination induces significant changes in the physiochemical properties of starch due to $\boldsymbol{\alpha}$-amylase activities, which contributes to degradation of starch molecules. Therefore, the objective of this study was to compare laboratory-induced wheat grain germination and pre-harvest sprouting in the field and their effects on starch characteristics and application in films.

\section{Experimental Section}

\subsection{Material}

Wheat grains from the same lot of cultivar BRS Marcante (Triticum aestivum L.) subjected to pre-harvest sprouting (PHS), laboratory-induced germination (IG), as well as non-germinated (NG) controls were used. Wheat was supplied by Embrapa Trigo, Passo Fundo, RS, Brazil.

\subsection{Germination of Wheat Grains}

Wheat germination was carried out according to methods described by Baranzelli et al. ${ }^{[7]}$ Wheat grains were initially immersed in $1 \%(\mathrm{v} / \mathrm{v})$ sodium hypochlorite solution (4-6\% active chlorine) for $15 \mathrm{~min}$. Subsequently, the grains were washed with distilled water until a $\mathrm{pH}$ of 7.0 was reached; grains were incubated for 24,48 , and $72 \mathrm{~h}$ at $30 \%$ moisture and $80 \%$ relative humidity; temperatures altered between 15 and $20^{\circ} \mathrm{C}$ in $12 \mathrm{~h}$ intervals, and samples were kept in the dark. Samples were then dried in the oven with an air circulation temperature of $40{ }^{\circ} \mathrm{C}$ until grains reached $12 \%$ moisture. The samples used were as follows: IG-24 (induced germination for $24 \mathrm{~h}$ ), IG-48 (induced germination for $48 \mathrm{~h}$ ), and IG-72 (induced germination for $72 \mathrm{~h}$ ).

\subsection{Extraction of Starch}

Wheat grains conditioned at $15 \%$ moisture for $24 \mathrm{~h}$ were milled in an experimental mill (Chopin, Moulin CD1, $n^{\circ} 1197$, Brazil) to obtain wheat flour. Wheat starch was extracted according to processes outlined by Baranzelli et al. ${ }^{[7]}$ Briefly, a mixture of wheat flour $(250 \mathrm{~g})$ and saline solution $(100 \mathrm{~mL} 2 \% \mathrm{NaCl}$ solution, w/v) was prepared and allowed to rest for approximately 30 min. The mass formed was "washed" with water until complete removal of the starch. The starch suspension was filtered through a $200 \mu \mathrm{m}$ mesh screen. The filtrate was centrifuged at $2000 \mathrm{~g}$ for $20 \mathrm{~min}$, after which the top layer was removed and the decanted material was resuspended in distilled water; this procedure was repeated three times. The starch was dried in an oven with air circulating at $40^{\circ} \mathrm{C}$ until a moisture content of $12 \%$ was achieved. The yield of this extraction procedure was determined as a ratio of total amount of flour and the amount of extracted starch; results were expressed as a percentage.

\subsection{Chemical Composition and of Starches}

The moisture, ash, lipid, and crude protein contents were determined according to AACC International ${ }^{[14]}$ methods 44 $15.02,08-12.01,30-25.01$, and 46-13.01, respectively. The amylose content was determined via the colorimetric method with iodine, according to methods published by McGrane, Cornell, and Rix ${ }^{[15]}$ with some modifications suggested by Hoover and Ratnayake. ${ }^{[16]}$

The determination of reducing sugars was accomplished by the DNS method, ${ }^{[17]}$ with some modifications. An aliquot of $200 \mu \mathrm{L}$ of starch solution was collected, adding $200 \mu \mathrm{L}$ of DNS solution (dinitro salicylic acid). Then, this solution was heated in a water bath at $100^{\circ} \mathrm{C}$ for $5 \mathrm{~min}$ and subsequently cooled in cold water. After that, $1.6 \mathrm{~mL}$ of distilled water was added and the spectrophotometric reading was performed at $540 \mathrm{~nm}$. The results were expressed in $\mathrm{mg}$ equivalent of reduced sugar per $\mathrm{mL}$ of sample, by performing the standard curve of glucose.

\subsection{Enzymatic Activity of Wheat Flours and Starch}

Determination of total amylolytic activity of the $\boldsymbol{\alpha}$-amylase enzyme was carried out according to methods outlined by Saman, Vázquez, and Pandiella. ${ }^{[18]}$ A unit of total amylolytic activity (AU) of $\alpha$-amylase was defined as the amount of enzyme required to release one $\mu \mathrm{mol}$ of maltose per minute.

\subsection{Morphology, Solubility, and Swelling Power of Starches}

The morphology of starch granules was evaluated by scanning electron microscopy (JSM-6610LV; Jeol Inc., Peabody, MA, USA).

The swelling power and solubility of starches were determined at $90^{\circ} \mathrm{C}$ according to the method described by Leach et al. ${ }^{[19]}$ Solubility was calculated as the ratio between residual and initial starch masses, and the results were expressed as a percentage. The swelling power was defined as the ratio between the swollen final mass and the initial starch mass, minus the amount of soluble starch.

\subsection{Pasting Properties of Starches}

The pasting properties of wheat starches were evaluated using a rapid viscosity analyzer (RVA-3D, Newport Scientific, Australia) equipped with the Thermocline software for Windows, version 3.1, according to the AACC International method 76-21.01. ${ }^{[14]}$ Pasting properties of samples were evaluated using distilled water with silver nitrate $\left(\mathrm{AgNO}_{3} / 100 \mu \mathrm{molg}^{-1}\right.$ starch). The silver nitrate solution was used to inhibit the activity of alpha amylase during RVA analysis, as described by Paraginski et al. ${ }^{[20]}$

\subsection{Thermal Properties of Starches}

Gelatinization characteristics of starches were determined by differential scanning calorimetry (TA-60WS, Shimadzu, Japan). 
Starch samples (approximately $2.5 \mathrm{mg}$, dry basis) were weighed directly into an aluminum pan, and distilled water was added to achieve a starch-water ratio of $1: 3(\mathrm{w} / \mathrm{w})$. The pan was hermetically sealed and allowed to equilibrate for $1 \mathrm{~h}$ prior to analysis. Sample pans were then heated from 30 to $120^{\circ} \mathrm{C}$ at a rate of $10^{\circ} \mathrm{C} \mathrm{min}^{-1}$. An empty pan was used as the control. The temperature at the onset of gelatinization $\left(\mathrm{T}_{\mathrm{o}}\right)$, peak temperature $\left(\mathrm{T}_{\mathrm{p}}\right)$, final temperature of gelatinization $\left(\mathrm{T}_{\mathrm{f}}\right)$, and gelatinization enthalpy $(\Delta H)$ were determined.

\subsection{X-Ray Diffraction Patterns and Relative Crystallinity of Starches}

X-ray diffraction patterns of starches were obtained with an X-ray diffractometer (XRD-6000, Shimadzu, Brazil). The diffraction scanning region varied between 5 and $30^{\circ}$; a voltage of $30 \mathrm{kV}$, a current of $30 \mathrm{~mA}$ and a scan speed of $1^{\circ} \mathrm{min}^{-1}$ was used. The relative crystallinity index (RC) of starch granules was quantitatively estimated according to the method proposed by Rabek. ${ }^{[21]} \mathrm{RC}$ was defined as the ratio between the area of the crystalline region (Ac) and the total area covered by $(\mathrm{Ac}+\mathrm{Aa})$, where Ac was the area of the crystalline region, and Aa was the area of the amorphous region; $R C(\%)=(A c /(A c+A a))^{*} 100$.

\subsection{Elaboration of the Films of Wheat Starches}

Starch films were prepared using the casting technique. The solution for film was prepared by dissolving $3 \mathrm{~g}$ starch and $0.9 \mathrm{~g}$ glycerol in $100 \mathrm{~mL}$ of water. This mixture was heated in a water bath (Fisatam, 550, Brazil) at $85^{\circ} \mathrm{C}$ for $15 \mathrm{~min}$. The solution was then homogenized in ultra turrax (IKA, T18 Basic, Germany) at $14000 \mathrm{rpm}$ for $10 \mathrm{~min}$. Aliquots of the solution $(20 \mathrm{~g})$ were mirrored onto $9 \mathrm{~cm}$ diameter Peter plates. The plates were then dried in an oven (Ethik, 420TD, Brazil) with air circulating at $30^{\circ} \mathrm{C}$ for approximately $16 \mathrm{~h}$. Films were then stored for $48 \mathrm{~h}$ at approximately $16^{\circ} \mathrm{C}$ and $60 \%$ humidity prior to evaluations.

\subsection{Opacity, Solubility, and Thickness of the Films}

Opacity of the films was determined using a colorimeter (MINOLTA, CR-400, Japan) according to methods by Konica Minolta, ${ }^{[22]}$ and was represented by the relationship between the opacity of films superimposed on black and white patterns. ${ }^{[23]}$

Films were cut in a $2.5 \mathrm{~cm}$ diameter circle and were dried in an oven at $105^{\circ} \mathrm{C}$ for $24 \mathrm{~h}$. Subsequently, films were transferred into Falcon tubes, and $50 \mathrm{~mL}$ distilled water was added. The tubes were stirred on a horizontal shaker at $175 \mathrm{rpm}$ and $25^{\circ} \mathrm{C}$ for $24 \mathrm{~h}$. Films were then removed from the aqueous medium, and were dried in an oven at $105^{\circ} \mathrm{C}$ until constant weight. Solubility was calculated as the ratio between the initial and final masses of the films, and the result was expressed as a percentage. ${ }^{[24]}$ Thickness was determined with a digital micrometer. Ten measurements were conducted in each treatment group, and results were expressed in $\mathrm{mm}$.

\subsection{Mechanical Properties of Films}

The tensile strength and elongation of films were determined using a texturometer (TA.TX Plus, Texture Analyzer) according to the ATM D 882 method. Films were cut into $2.5 \times 8.5 \mathrm{~cm}$ strips, and 10 films from each treatment were used for analysis. Films were fixed in the texturometer; initial separation of the claws was $5 \mathrm{~cm}$, velocity of the probe was $1 \mathrm{~mm} \mathrm{~s}^{-1}$. Tensile strength of the film was calculated as the quotient of maximum force at moment of rupture and the cross-sectional area. Elongation was calculated as the difference between the distance reached by the probe at moment of rupture and the initial distance $(5 \mathrm{~cm})$; results were expressed as a percentages.

\subsection{Water Vapor Permeability (WVP) and Moisture of Films}

Water vapor permeability of films was determined by the ASTM method E-96-95. ${ }^{[25]}$ Calcium chloride with $0 \%$ relative humidity was placed on aluminum permeation cells, and films were sealed with paraffin. Cells were placed in desiccators at $25^{\circ} \mathrm{C}$ with $75 \%$ relative humidity, which was maintained using a saturated sodium chloride solution. The permeability to water vapor was determined in triplicates during the 48-h incubation period, according to Equation (1),

$W V P=\frac{\Delta w}{t} \times \frac{x}{a \Delta P}$

where WVP is permeability to water vapor (g.mm $/ \mathrm{kPa} \cdot$ day. $\mathrm{m}^{2}$ ), $\Delta W$ is the mass gain (g), $x$ is film thickness (mm), $t$ is time (days), $a$ is exposed area $\left(\mathrm{m}^{2}\right)$, and $\Delta P$ is the partial pressure difference $(\mathrm{kPa})$.

Moisture content was determined by measuring the weight loss of the film, after drying it in an oven at $105^{\circ} \mathrm{C}$ until the weight was constant. The results were expressed as a percentage of the moisture content of the samples.

\subsection{Statistical Analysis}

Results were analyzed by analysis of variance (ANOVA), and the means were compared using Tukey's post-hoc test with a significance level of $5 \%$.

\section{Results and Discussion}

\subsection{Enzymatic Activity of Wheat Flours and Starches}

The effect of pre-harvest sprouting and induced germination on starch was evaluated via enzymatic activity. As shown in Figure 1, germination significantly increased alpha amylase activity, both in induced germination (IG) and pre-harvest sprouting (PHS) starches. In addition, highest alpha amylase activity was observed in starch subjected to $72 \mathrm{~h}$ induced germination (IG-72). These results were comparable to that described in literature, where increased alpha amylase activity was observed 


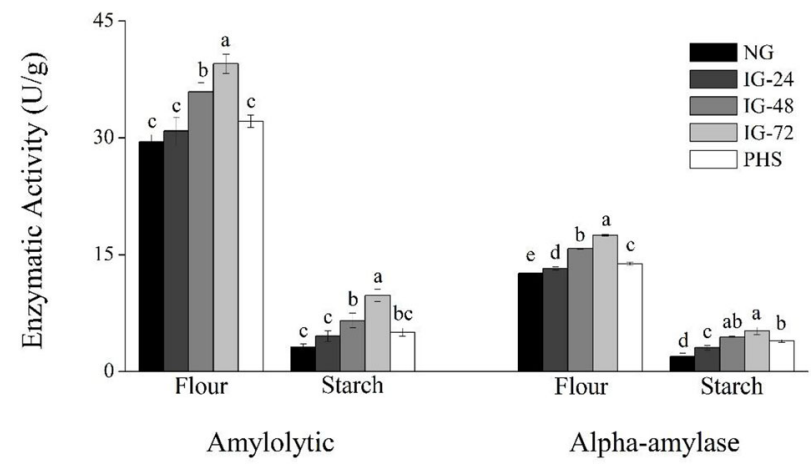

Figure 1. Total amylolytic activity and a-amylase of starch NG (nongerminated), IG-24 (induced germination by $24 \mathrm{~h}$ ), IG-48 (induced germination by $48 \mathrm{~h}$ ) and IG-72 (induced germination by $72 \mathrm{~h}$ ) and preharvest sprouting (PHS).

with germination..$^{[7,8,12]}$ Ding et al. ${ }^{[8]}$ has previously estimated alpha amylase activity in germinated wheat grains by measuring the falling number. These authors reported an inverse relationship between the falling number and germination time, suggesting that activity of alpha amylase increases with germination time. The alpha amylase activity of starch obtained from PHS was lower as compared with that of IG-72. Depending on the germinating conditions in the laboratory, such as relative humidity, time, and temperature, it was possible to obtain amylolytic activity similar to that of PHS wheat.

Total amylolytic activity and alpha amylase of refined wheat flour were higher as compared with those of starch, since the majority of amylolytic enzymes were removed during the starch extraction process. Moreover, $24 \mathrm{~h}$ of induced germination did not have any effect on amylolytic activity; however, IG-48 and IG-72 significantly increased total amylolytic activity in refined flour and starch (Figure 1). According to Delcour and Hoseney, ${ }^{[26]}$ amylases are distributed throughout the wheat plant; they are mainly localized in the germ and pericarp of grains, and in the presence of water, migrate to regions rich in starch, proteins, and lipids, where they initiate hydrolytic processes for energy production.

\subsection{Characterization of Starches}

The extraction yields and chemical compositions of wheat starches are shown in Table 1 . Germination of wheat did not significantly affect starch extraction yield (Table 1). We found that amylose content was lower in starch samples obtained from IG-72 grains when compared with those of others. This reduction in amylose content is due to enzymatic degradation of starch to maintain the physiological needs of the plant during growth. It is possible that degradation of starch in the IG-24 and IG-48 groups, as well as the PHS group, was not sufficient to induce changes in amylose content and extraction yield of starch. Wu et al. ${ }^{[27]}$ evaluated the effects of germination time on the physicochemical properties of starch from different rice cultivars and observed a decrease in amylose content with increased germinated time.

The starches presented very low levels of ash $(0.13-0.21 \%)$, lipids $(0.10-0.13 \%)$, and proteins $(0.31-0.37 \%)$, which was indicative of efficient extraction method (Table 1 ). The purity of wheat starch samples was determined based on protein and ash contents, which were approximately 0.30 and $0.36 \%$, respectively, therefore, samples were considered to be of high purity. ${ }^{[2]}$

Starches obtained from IG-24 showed significantly higher swelling power when compared with those obtained from PHS wheat. Xie et al. ${ }^{[28]}$ demonstrated a positive relationship between the amount of small granules present in starch samples and the swelling power. These authors attributed this relationship to the surface area of starch granules; it was proposed that the greater the number of small granules, the greater the area of contact, which consequently leads to greater water absorption. This relationship may have also contributed to our findings, which showed that starch obtained from IG wheat presented greater number of small granules, whereas PHS wheat starch exhibited predominantly large granules (Figure 2).

The solubility of starches increased with wheat germination (IG-24 and PHS), when compared with those of non-germinated wheat. It is possible that the rough surfaces and small holes in starch granules (Figure 2) promoted water penetration, which facilitated solubilization of the interior. In addition, germination may also have contributed to increased solubility by degrading starch into smaller sugars, which rendered it more soluble.

Table 1. Extraction yield, amylose content, reducing sugar, chemical composition, swelling power, and solubility of non-germinated and germinated wheat starches (induced germination and pre-harvest sprouting).

\begin{tabular}{lcccrc}
\hline Parameters & NG & IG-24 & IG-48 & IG-72 \\
\hline Extraction yield [\%] & $50.20 \pm 1.27^{\mathrm{ab}}$ & $52.20 \pm 2.40^{\mathrm{a}}$ & $49.00 \pm 0.72^{\mathrm{ab}}$ & $46.60 \pm 1.31^{\mathrm{b}}$ & $45.83 \pm 1.35^{\mathrm{b}}$ \\
Amylose [\%] & $34.77 \pm 1.01^{\mathrm{a}}$ & $33.63 \pm 1.87^{\mathrm{a}}$ & $34.70 \pm 1.48^{\mathrm{a}}$ & $30.81 \pm 1.50^{\mathrm{b}}$ & $35.56 \pm 0.30^{\mathrm{a}}$ \\
Reducing sugar [mg mL $\left.{ }^{-1}\right]^{\mathrm{b})}$ & $0.09 \pm 0.00^{\mathrm{d}}$ & $0.19 \pm 0.01^{\mathrm{c}}$ & $0.34 \pm 0.02^{\mathrm{b}}$ & $0.50 \pm 0.01^{\mathrm{a}}$ & $0.13 \pm 0.01^{\mathrm{d}}$ \\
Moisture [\%] & $8.73 \pm 0.21^{\mathrm{d}}$ & $12.35 \pm 0.19^{\mathrm{a}}$ & $11.36 \pm 0.50^{\mathrm{b}}$ & $10.65 \pm 0.03^{\mathrm{c}}$ & $8.96 \pm 0.25^{\mathrm{d}}$ \\
Ash [\%] & $0.14 \pm 0.01^{\mathrm{b}}$ & $0.13 \pm 0.00^{\mathrm{c}}$ & $0.13 \pm 0.00^{\mathrm{c}}$ & $0.13 \pm 0.00^{\mathrm{c}}$ & $0.21 \pm 0.01^{\mathrm{a}}$ \\
Lipids [\%]) & $0.10 \pm 0.00^{\mathrm{d}}$ & $0.13 \pm 0.01^{\mathrm{a}}$ & $0.13 \pm 0.01^{\mathrm{ab}}$ & $0.12 \pm 0.00^{\mathrm{b}}$ & $0.11 \pm 0.00^{\mathrm{c}}$ \\
Protein [\% Nx 5.7] & $0.33 \pm 0.01^{\mathrm{bc}}$ & $0.34 \pm 0.01^{\mathrm{ab}}$ & $0.37 \pm 0.01^{\mathrm{a}}$ & $0.34 \pm 0.01^{\mathrm{ab}}$ & $0.31 \pm 0.02^{\mathrm{c}}$ \\
Swelling power [g/g] & $7.62 \pm 0.20^{\mathrm{ab}}$ & $8.17 \pm 0.30^{\mathrm{a}}$ & $7.74 \pm 0.28^{\mathrm{ab}}$ & $7.93 \pm 0.34^{\mathrm{ab}}$ & $7.43 \pm 0.14^{\mathrm{b}}$ \\
Solubility [\%] & $4.00 \pm 0.19^{\mathrm{b}}$ & $4.81 \pm 0.23^{\mathrm{a}}$ & $4.48 \pm 0.13^{\mathrm{ab}}$ & $4.34 \pm 0.20^{\mathrm{ab}}$ & $4.55 \pm 0.22^{\mathrm{a}}$ \\
\hline
\end{tabular}

NG, non-germinated; IG-24, induced germination by 24 h; IG-48, induced germination by 48 h; IG-72, induced germination by 72 h; PHS, pre-harvest sprouting.

a) Means followed by the same letters in the same line do not differ statistically by the Tukey test at $5 \%$ significance. The ash, lipid, protein and extractive yield results are expressed as dry matter (\%, b.s.). ${ }^{\text {b) }} \mathrm{mg}$ of glucose for $\mathrm{mL}$ of sample solution. 

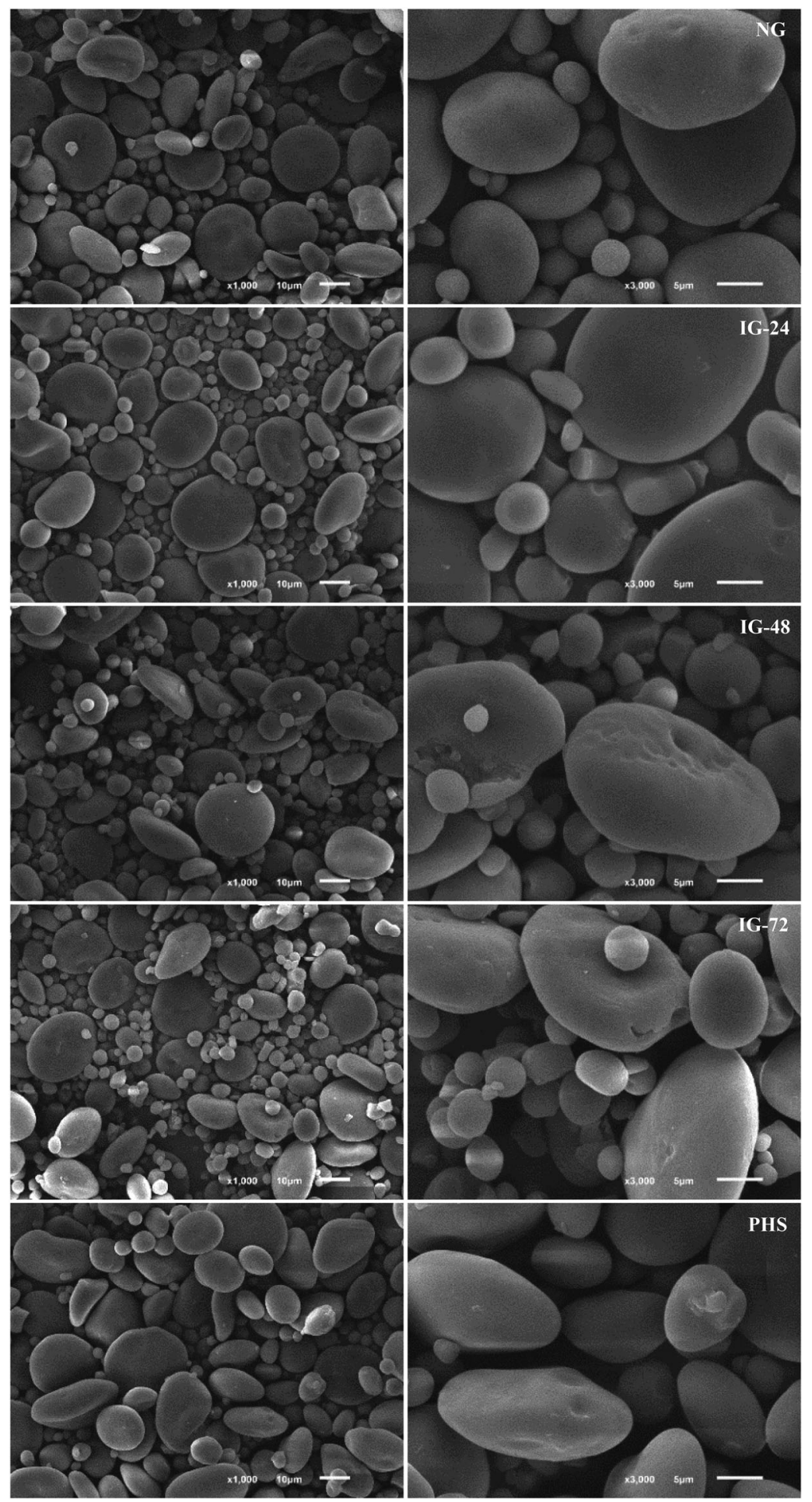

Figure 2. Morphology of starch granules NG (non-germinated), IG-24 (induced germination by $24 \mathrm{~h}$ ), IG-48 (induced germination by $48 \mathrm{~h}$ ) and IG-72 (induced germination by $72 \mathrm{~h}$ ) and pre-harvest sprouting (PHS), in magnification of $1000 x$ and $3000 x$.

\subsection{Morphology of Starches}

Scanning electron micrographs of the surfaces of wheat starch granules are shown in Figure 2. The starch granules exhibited typical characteristics of wheat $\operatorname{starch}^{[29]}$ with bimodal size distribution. Larger granules were lenticular in shape and were approximately 20-35 $\mu \mathrm{m}$ diameter (starch A). Smaller granules were spherical and were $2-8 \mu \mathrm{m}$ in diameter (starch B). The germination process affected granule size since samples from IG wheat presented a greater percentage of small granules as compared with those obtained from PHS and NG wheat. Regardless of the process and the degree of germination, starch granules were comparable in morphology.

NG and IG-24 wheat starch granules exhibited smooth surfaces. A slight surface modification in starch granules was found in IG-48 wheat, where a rougher surface with small holes was observed (Figure 2). Enzymes generally cause cracks and pores in starch granules; this promotes solubilization of the interior and exo-corrosion of the granular surface. As a result, the external region increases in brittleness, and the diameter of the starch granule is reduced.

\subsection{Pasting Properties of Starches}

The pasting properties of starches are presented in Table 2. The starch of NG wheat showed lower pasting temperature as compared to that obtained from starch of germinated grains (Table 2). This is associated with partial enzymatic degradation of starch during wheat germination. In addition, the higher lipid content present in starch isolates of germinated wheat can contribute to higher pasting temperature, since lipids tend to complex with amylose on the surface of granules and decrease their interactions with water. ${ }^{[28]}$

Starches from germinated wheat presented lower peak viscosity when compared to NG starch. This decrease in peak viscosity can be explained due to enzymatic degradation of starch, since amylases are enzymes of endogenous action; they hydrolyze the interior of the starch molecules and therefore reducing the viscosity. ${ }^{[30]}$ Ding et al. ${ }^{[8]}$ evaluated the effect of three wheat germination processes on the quality of whole wheat flours; results indicated that low peak viscosity is associated to the increase of enzymatic activity.

We observed that IG of wheat increased breakdown of starches; however, starch obtained from PHS was compared to that of NG wheat starch. PHS wheat starch presented lower retrogradation as compared with that of NG and IG wheat starches (IG-24 and IG-48). These parameters are important when starch is used as a food ingredient. It should be noted that amylose and amylopectin molecules contribute to the texture and physical properties of foods. ${ }^{[31]}$ The lower tendency for retrogradation may be indicative of better quality of food products. 
Table 2. Pasting properties of non-germinated and germinated wheat starches (induced germination and pre-harvest sprouting).

\begin{tabular}{|c|c|c|c|}
\hline$\overline{\text { Parameters }^{\text {a) }}}$ & Starch & Without $\mathrm{AgNO}_{3}$ & $\overline{\text { With } \mathrm{AgNO}_{3}}$ \\
\hline \multirow[t]{5}{*}{ Pasting temperature $\left({ }^{\circ} \mathrm{C}\right)$} & NG & $81.75 \pm 0.52 b$ & $80.70 \pm 0.85 c$ \\
\hline & IG-24 & $85.83 \pm 0.49 a$ & $85.53 \pm 0.02 b$ \\
\hline & IG-48 & $86.36 \pm 0.85 a$ & $85.43 \pm 0.13 b$ \\
\hline & IG-72 & $86.07 \pm 0.90 a$ & $87.40 \pm 0.10 a$ \\
\hline & PHS & $86.08 \pm 0.97 a$ & $85.58 \pm 0.02 b$ \\
\hline \multirow[t]{5}{*}{ Peak viscosity (RVU) } & NG & $276.59 \pm 3.30 \mathrm{a}$ & $276.09 \pm 1.59 b$ \\
\hline & IG-24 & $243.04 \pm 0.30 c$ & $273.67 \pm 1.00 \mathrm{~b}$ \\
\hline & IG-48 & $229.17 \pm 1.41 d$ & $273.71 \pm 0.54 b$ \\
\hline & IG-72 & $238.00 \pm 2.12 c$ & $259.46 \pm 3.04 c$ \\
\hline & PHS & $251.21 \pm 4.89 b$ & $281.25 \pm 1.92 \mathrm{a}$ \\
\hline \multirow[t]{5}{*}{ Breakdrown (RVU) } & NG & $40.55 \pm 1.77 b$ & $50.54 \pm 6.54 b$ \\
\hline & IG-24 & $46.94 \pm 2.91 \mathrm{ab}$ & $67.63 \pm 3.21 a$ \\
\hline & IG-48 & $49.92 \pm 2.50 a$ & $63.96 \pm 5.29 a$ \\
\hline & IG-72 & $50.34 \pm 2.84 a$ & $57.09 \pm 1.84 \mathrm{ab}$ \\
\hline & PHS & $40.42 \pm 2.45 b$ & $49.71 \pm 0.29 b$ \\
\hline \multirow[t]{5}{*}{ Final viscosity (RVU) } & NG & $327.00 \pm 0.11 a$ & $336.08 \pm 0.01 a$ \\
\hline & IG-24 & $291.86 \pm 1.17 b$ & $317.13 \pm 2.38 \mathrm{~b}$ \\
\hline & IG-48 & $277.72 \pm 2.36 \mathrm{~d}$ & $313.09 \pm 4.91 \mathrm{~b}$ \\
\hline & IG-72 & $274.59 \pm 2.60 d$ & $297.71 \pm 0.38 c$ \\
\hline & PHS & $285.59 \pm 4.72 c$ & $331.42 \pm 1.34 \mathrm{a}$ \\
\hline \multirow[t]{5}{*}{ Retrogradation (RVU) } & NG & $91.06 \pm 3.11 \mathrm{a}$ & $100.21 \pm 5.38 \mathrm{~b}$ \\
\hline & IG-24 & $97.58 \pm 2.93 a$ & $111.09 \pm 1.84 a$ \\
\hline & IG-48 & $97.71 \pm 4.89 \mathrm{a}$ & $100.34 \pm 2.84 b$ \\
\hline & IG-72 & $85.38 \pm 10.54 a b$ & $102.83 \pm 2.25 b$ \\
\hline & PHS & $72.61 \pm 5.91 b$ & $101.84 \pm 1.17 \mathrm{~b}$ \\
\hline
\end{tabular}

NG, non-germinated; IG-24, induced germination by $24 \mathrm{~h}$; IG-48, induced germination by $48 \mathrm{~h}$ and IG-72, induced germination by $72 \mathrm{~h}$; PHS, pre-harvest sprouting.

${ }^{\text {a) }}$ Means followed by the same letters in the same column do not differ statistically by the Tukey test at $5 \%$ significance.

Silver nitrate analysis was performed to examine the behavior of starches from germinated and NG wheat without the effect of $\alpha$ amylase. Peak viscosity, breakdown, final viscosity, and retrogradation of starches all increased with the addition of silver nitrate when compared with those of starches analyzed without silver nitrate; this was indicative of $\alpha$-amylase action during RVA analysis. Furthermore, differences in these variables were observed between germinated and NG wheat starches, possibly due to $\alpha$-amylase actions during the germination process.

\subsection{Thermal Properties of Starches}

The gelatinization properties of starches are presented in Table 3. PHS starches presented the lowest gelatinization temperature. According to Li et al., ${ }^{[32]}$ gelatinization temperature is negatively correlated with amylose contents. This was confirmed in our current study (Table 1), where starch with
Table 3. Thermal properties of non-germinated and germinated wheat starches (induced germination and pre-harvest sprouting).

\begin{tabular}{llllc}
\hline & \multicolumn{3}{c}{ Gelatinization temperatures } & \\
\cline { 2 - 4 } Starch & $\mathrm{T}_{\mathrm{p}}\left[{ }^{\circ} \mathrm{C}\right]$ & $\mathrm{T}_{\circ}\left[{ }^{\circ} \mathrm{C}\right]$ & $\mathrm{T}_{\mathrm{f}}\left[{ }^{\circ} \mathrm{C}\right]$ & Enthalpy $\left[\mathrm{g} \mathrm{g}^{-1}\right]$ \\
\hline NG & 60.42 & 56.35 & 65.16 & -5.34 \\
IG-24 & 60.61 & 56.36 & 64.14 & -4.72 \\
IG-48 & 61.20 & 56.99 & 64.47 & -4.07 \\
IG-72 & 61.23 & 57.54 & 64.99 & -3.54 \\
PHS & 59.24 & 54.72 & 63.93 & -5.06 \\
\hline
\end{tabular}

lower amylose content exhibited higher gelatinization temperature (IG-72 starch). All germinated starches showed an increase in gelatinization properties $\left(\mathrm{T}_{\mathrm{p}}\right.$ and $\left.\mathrm{T}_{0}\right)$ as compared with those of NG and PHS wheat starches.

Germinated wheat starches showed lower gelatinization enthalpy as compared with that of NG and of PHS wheat starches, which suggested that the energy required for gelatinization decreases with increased germination time. This reduction in gelatinization enthalpy is a consequence of substantial breakdown of starch molecules and lower proportion of amorphous chains as a result of enzymatic actions during wheat germination. ${ }^{[8]}$

However, these results differ from those reported by Pinkaew et al., ${ }^{[10]}$ who suggested that an increase in gelatinization temperatures and enthalpy is associated with increased relative crystallinity. According to these authors, the increase in gelatinization temperatures and enthalpy may be due to a decrease in short chains and consequent increase in amylopectin branch chains. These different findings may be influenced by germination conditions and differences in the evaluated starch sources (rice vs. wheat). Stricter germination conditions could induce more changes in gelatinization temperatures and enthalpy.

\subsection{X-Ray Diffraction Patterns and Relative Crystallinity of Starches}

X-ray diffraction patterns and relative crystallinity (RC) of starches are shown in Figure 3. The curves are typical of starch type A, since they present intense peaks at $15^{\circ}, 17^{\circ}, 18^{\circ}$, and $23^{\circ}$, which are characteristic of cereal starches. Generally, the crystalline region of a starch is associated its amylopectin content, while the amorphous region is represented by amylose. ${ }^{[33]}$ The relative crystallinity of starches was altered by induced wheat germination; starch obtained from IG-72 presented higher relative crystallinity $(24.4 \%)$, when compared with those of other samples. This increase in relative crystallinity may be due to lower amylose content (Table 1). Thus, our results suggested that induced germination alters amylose/amylopectin ratio as consequence of starch degradation by enzymatic action (Figure 1). Pinkaew et al. ${ }^{[10]}$ evaluated three types of starches in pre-germinated rice with different amylose contents and observed an increase in relative crystallinity in all samples as a result of germination. 


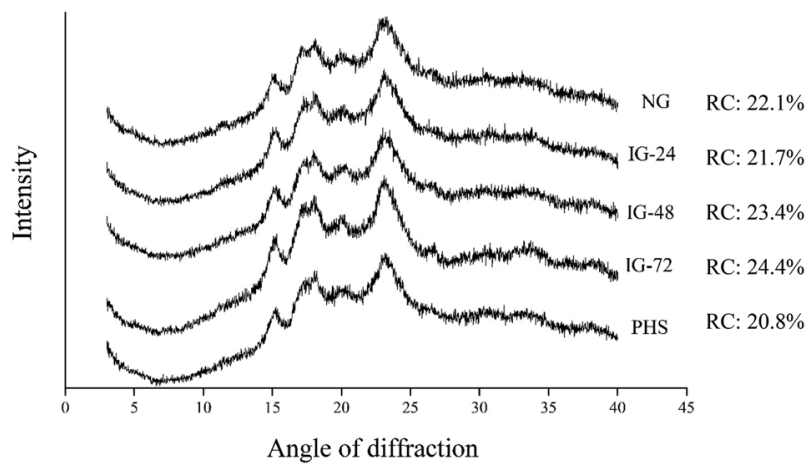

Figure 3. X-ray diffractogram of NG (non-germinated), IG-24 (induced germination by $24 \mathrm{~h}$ ), IG-48 (induced germination by $48 \mathrm{~h}$ ) and IG-72 (induced germination by $72 \mathrm{~h}$ ) and pre-harvest sprouting (PHS).

\subsection{Characterization of Starch Films}

Films were developed with NG wheat starches and starches obtained from IG-24, IG-48, and IG-72 samples (Table 4); starch obtained from PHS grains was not used. The choice of using only starches from NG wheat and wheat germinated in the laboratory was based on process control and degree of germination using standardized conditions in terms of time, temperature, relative humidity, among others.

The tensile strength of starch films was not associated with wheat germination time. The IG-48 wheat starch film was the most resistant among all starch films examined. Basiak, Lenart, and Debeaufort ${ }^{[34]}$ have previously evaluated the effect of starch source (corn, wheat and potato) on film characteristics, including mechanical properties. These authors reported that mechanical properties are dependent on water content due to the hydrophilic nature of starch films. It is possible that starch obtained from germinated grains have more sites available for interactions with water molecules.

In addition, the intermolecular association of starch, especially among the amylose molecules, may provide greater structural integrity in the polymer matrix and thus enhance the tensile strength of the films. However, the germination for longer times (IG-72) resulted in a higher depolymerization of the starch molecule and forming reducing sugar (Table 1), and thus resulting in a reduction in tensile strength of the film (Table 4).
The same authors reported a tensile strength of 3.29 MPa for wheat starch film. This was higher than that found in our study; we recorded $1.50 \mathrm{MPa}$ for film obtained from NG wheat starch and 2.67 MPa for film obtained from IG-48 wheat starch. Several other factors may also influence the tensile strength of films, such as the plasticizer content used in the formulation, the thickness of the films, and the presence of additives; this may explain the difference among the results.

Elongation of starch films increased significantly with wheat germination time, which is an attractive characteristic for future applications. According to Bertuzzi, Armada, and Gottifredi, ${ }^{[35]}$ the intermolecular association of starch, especially among the amylose molecules, makes the film more rigid. During the germination process, as part of the starch is damaged by enzymatic actions (Figure 1), the amylose and amylopectin molecules are reduced to simple sugars. The higher elongation property of IG-72 wheat starch films may be associated with its higher reducing sugar content (Table 1), since these small molecules act as plasticizer, owing its hydroxyl groups which easily retain water into film matrix during the drying process, thereby increase elongation of the films. ${ }^{[36]}$ However, the moisture content of films, even being considered a plasticizer, did not influence the elongation of IG-72 wheat starch films.

The thickness of starch films obtained from IG-72 wheat starch was higher as compared with that of NG wheat starch films, despite using the same mass/surface ratio at the time of molding. The greater thickness of the film may be associated with higher moisture content of the films. Increased interactions between starch and water molecules in starch films of germinated wheat may contribute to the increase in thickness.

The germination process did not significantly affect the opacity, water solubility, and water vapor permeability of films. Solubility measurement of films is important interactions between the film and water establish the integrity of films. Basiak, Lenart, and Debeaufort ${ }^{[34]}$ reported that film solubility depends on starch source and amylose content. While wheat germination led to a reduction in amylose content of IG-72 wheat, this variation was not sufficient to cause changes in water solubility of films.

The results of water vapor permeability suggested that the arrangement of polymer chains in germinated wheat starch films is similar to that of NG wheat starch. Therefore, the germination process does not affect water transfer through the empty spaces in films.

Table 4. Mechanical properties, thickness, opacity, solubility in water, water vapor permeability and moisture content of the films of nongerminated and germinated wheat starches.

\begin{tabular}{|c|c|c|c|c|c|c|c|}
\hline Starch films ${ }^{\text {a) }}$ & Tensile strength [MPa] & Elongation [\%] & Thickness [mm] & Opacity [\%] & Solubility [\%] & WVP [g.mm/kPa.day.m ${ }^{2}$ ] & Moisture content (\%) \\
\hline NG & $1.50 \pm 0.05 b$ & $55.6 \pm 7.7 c$ & $0.093 \pm 0.005 b$ & $11.3 \pm 0.4 \mathrm{a}$ & $38.9 \pm 0.8 \mathrm{a}$ & $1.85 \pm 0.05 a$ & $19.11 \pm 0.85 b$ \\
\hline IG-24 & $1.53 \pm 0.12 b$ & $76.6 \pm 7.1 \mathrm{bc}$ & $0.097 \pm 0.003 \mathrm{ab}$ & $11.8 \pm 0.4 \mathrm{a}$ & $36.6 \pm 1.3 a$ & $1.72 \pm 0.15 a$ & $22.51 \pm 0.07 \mathrm{a}$ \\
\hline IG-48 & $2.67 \pm 0.16 a$ & $89.8 \pm 17.8 \mathrm{ab}$ & $0.098 \pm 0.010 \mathrm{ab}$ & $11.5 \pm 0.5 a$ & $39.8 \pm 1.4 a$ & $1.65 \pm 0.04 a$ & $23.39 \pm 0.30 \mathrm{a}$ \\
\hline IG-72 & $1.53 \pm 0.11 b$ & $115.7 \pm 12.1 \mathrm{a}$ & $0.103 \pm 0.005 a$ & $11.7 \pm 0.7 a$ & $38.3 \pm 0.3 a$ & $1.82 \pm 0.12 a$ & $18.18 \pm 0.35 b$ \\
\hline
\end{tabular}

NG, non-germinated; IG-24, induced germination by $24 \mathrm{~h}$; IG-48, induced germination by $48 \mathrm{~h}$ and IG-72, induced germination by $72 \mathrm{~h}$; WVP, water vapor permeability.

a) Means followed by the same letters in the same column do not differ statistically by the Tukey test at $5 \%$ significance. 


\section{Conclusion}

The process of wheat germination produced in laboratories affects biochemical and mechanical properties of starch films. Germination increased enzymatic activity, swelling power, and solubility of starches and decreased their relative crystallinity. Starch films exhibited a significant increase in tensile strength and elongation due to the germination process. This study yielded promising results for future applications of starch films, especially in the packaging industry. In addition, the use of starch obtained from germinated wheat grains is an attractive proposition; it adds value to this product since germinated wheat is commonly discarded due to its inability to be used in baking.

\section{Acknowledgements}

This study was financed in part by the Coordenação de Aperfeiçoamento de Pessoal de Nível Superior-Brazil (CAPES)—Finance Code 001. We would like to thank CNPq and FAPERGS for their financial support.

\section{Conflict of Interest}

The authors declare no conflict of interest.

\section{Keywords}

amylolytic enzymes, films, germination, wheat starch

Received: September 17, 2018 Revised: October 29, 2018

Published online: March 3, 2019

[1] K. Bashir, T. L. Swer, K. S. Prakash, M. Aggarwal, LWT - Food Sci. Technol. 2017, 76, 131.

[2] W. Li, J. Gao, G. Wu, J. Zheng, S. Ouyang, Q. Luo, G. Zhang, Food Hydrocolloids 2016, 60, 364.

[3] A. Ubeyitogullari, O. N. Ciftci, Carbohyd. Polym. 2016, 147, 125.

[4] H. Angellier, S. Molina-Boisseau, P. Dole, A. Dufresne, Biomacromolecules 2006, 7, 531.

[5] J. Bonilla, L. Atarés, M. Vargas, A. Chiralt, J. Food Eng. 2013, 114, 303.

[6] S. L. M. Halal, R. Colussi, B. Biduski, J. A. Evangelho, G. P. Bruni, M. D. Antunes, A. R. G. Dias, E. R. Zavareze, J. Sci. Food Agric. 2017, 97, 411.

[7] J. Baranzelli, D. H. Kringel, R. Colussi, F. F. Paiva, B. C. Aranha, M. Z. Miranda, E. R. Zavareze, A. R. G. Dias, LWT - Food Sci. Technol. 2018, 90, 483.
[8] J. Ding, G. G. Hou, B. V. Nemzer, S. Xiong, A. Dubat, H. Feng, Food Chem. 2018, 243, 214.

[9] A. Marti, G. Cardone, A. Nicolodi, L. Quaglia, M. A. Pagani, LWT Food Sci. Technol. 2017, 80, 230.

[10] H. Pinkaew, Y. J. Wang, O. Naivikul, J. Cereal Sci. 2017, 73, 151.

[11] H. Olaerts, Y. Bondt, C. M. Courtin, Food Chem. 2018, 241, 434.

[12] S. Simsek, J. B. Ohm, H. Lu, M. Rugg, W. Berzonsky, M. S. Alamri, M. Mergoum, J. Sci. Food Agric. 2014, 94, 205.

[13] H. Olaerts, C. Roye, L. J. A. Derde, G. Sinnaeve, W. R. Meza, B. Bodson, C. M. Courtin, J. Agric. Food Chem. 2016, 64, 8324.

[14] AACC. Approved Methods of Analysis. AACC International, 11th ed., St. Paul, MN, U.S.A 2011.

[15] S. J. Mcgrane, H. J. Cornell, C. J. Rix, Starch-Starke. 1998, 50, 158.

[16] R. Hoover, W. Ratnayake, in Current protocols of food analytical chemistry. Unit E2.3. (Ed: R. E. Wrolstad), John Wiley and Sons, USA 2001.

[17] G. L. Miller, Anal. Chem. 1959, 31, 426.

[18] P. Saman, J. A. Vázquez, S. S. Pandiella, Process Biochem. 2008, 43, 1377.

[19] H. W. Leach, L. D. Mccowen, T. J. Schoch, Cereal Chem. 1959, 36, 534.

[20] R. T. Paraginski, J. A. Evangelho, R. Colussi, R. M. Silva, E. R. Zavareze, M. Oliveira, M. C. Elias, A. R. G. Dias, Starch/ Stärke. 2014, 60, 1.

[21] J. F. Rabek, Experimental Methods in Polymer Chemistry: Applications of Wide-Angle X-Ray Diffraction (WAXD) to the Study of the Structure of Polymers. Wiley Interscience, Chichester 1980.

[22] K. Minolta, Chroma meter CR-400/410. Instruction Manual. Japan 2013.

[23] Hunterlab. The color management company. Universal software, version 3.2. Reston. 1997.

[24] N. Gontard, C. Duches, J. L. Cuq, S. Guilbert, Int J Food Sci Tecnol. 1994, 29, 39

[25] ASTM. Annual Book of ASTM Standards. American Society for Testing and Materials, Philadelphia 1995.

[26] J. A. Delcour, R. C. Hoseney, Principles of Cereal Science and Technology, 3rd ed., EUA, St. Paul, Minessota 2010.

[27] F. Wu, H. Chen, N. Yang, J. Wang, X. Duan, Z. Jin, X. Xu, J. Cereal Sci. 2013, 58, 263.

[28] X. S. Xie, S. W. Cui, W. Li, R. Tsao, Food Res. Int. 2008, 41, 882.

[29] C. Li, C. Y. Li, R. Q. Zhang, W. Liang, X. L. Kang, Y. Jia, Y. C. Liao, J. Cereal Sci. 2015, 66, 66.

[30] D. Mares, K. Mrva, J. Cereal Sci. 2008, 47, 6.

[31] N. A. Bhat, I. A. Wani, A. M. Hamdani, A. Gani, F. A. Masoodi, LWTFood Sci. Technol. 2016, 71, 175.

[32] C. Li, S-G. Oh, D-H. Lee, H-W. Baik, H-J. Chung, Int. J. Biol. Macromol. 2017, 105, 931.

[33] H. F. Zobel, Starch/Stärke 1988, 40, 44.

[34] E. Basiak, A. Lenart, F. Debeaufort, Int. J. Biol. Macromol. 2017, 98, 348.

[35] M. A. Bertuzzi, M. Armada, J. C. Gottifredi, J. Food Eng. 2007, 82, 17.

[36] J. A. Sirviö, M. Visanko, J. Ukkola, H. Liimatainen, Ind. Crops Prod. 2018, 122, 513. 